\title{
Dynamic Modelling of a Solar Energy System with Vehicle to Home Option for Newfoundland Conditions
}

\author{
Raghul Suraj Sundararajan and M. Tariq Iqbal
}

\begin{abstract}
This paper discusses the dynamic modelling of a solar energy system with vehicle to home (V2H) option for Newfoundland condition. A location was chosen (13 Polina Road) in St. John's, Newfoundland, Canada. Using BEopt, Homer and MATLAB software, an optimized system was designed for the chosen site to satisfy the house's energy demand. Furthermore, the concept of $\mathrm{V} 2 \mathrm{H}$ is also implemented with aid of smart current sensors installed in the house. When the power provided by the PV panel and the stored energy in the inhouse battery is less than the load's energy demand, the Nissan Leaf's battery used to supply home loads in $\mathrm{V} 2 \mathrm{H}$ operation mode. The system operates based on the information generated by the sensors. Detailed system dynamic modelling is also presented along with the simulation results. Eight system control modes are proposed and simulated.
\end{abstract}

Index Terms - Hybrid power systems, PV, V2H, Renewable energy, dynamic modelling.

\section{INTRODUCTION}

Electric vehicles (EVs) are a revolutionary development in the global transportation industry. As compared to fossil fuel powered cars, they have more acceleration and emit no pollution, making them a reliable alternative. Renewable energy resources, such as solar energy systems can help meet the fast-growing energy demand in the fast-changing world. Renewables being variable in nature, there is a need for backup support [1]. Hence the need of battery storage comes into play. The inhouse battery is used to supply uninterrupted power to load when the power produced by PV is not sufficient to meet the loads energy demand [2]. Nissan Leaf (40 $\mathrm{kW}$ variant) is considered for the Vehicle to Home (V2H) concept implementation [3], [4]. Furthermore, the implemented system, during charging mode has level 1 and level 2 chargers for charging the Nissan Leaf's battery and a converter for simultaneously charging the inhouse battery and powering the load. By default, the designed system uses PV as primary source of power until the produced power is less than the load's energy demand. In this case the inhouse battery is used for powering the loads until it reaches $30 \%$ of its State of Charge (SOC). On reaching 30\% SOC the system will implement $\mathrm{V} 2 \mathrm{H}$, in this case Nissan leaf's battery will be in discharge mode to meet the load's energy demand [5]-[7].

In this paper, a system is designed, and its control algorithm is presented to address this issue of implementing Vehicle to Home concept along with hybrid PV system. The system sizing and dynamic modelling was carried out using BEopt, HOMER and MATLAB.

\section{Site Details ANd CAlculations}

\section{A. Selected Site}

A house at 13 Polina Road in St. John's, Newfoundland, Canada was chosen as the research venue. It covers an area of $185.89 \mathrm{~m}^{2}$. Fig. 1 displays a monthly profile of solar radiation and clearness index for the selected site in $\mathrm{St}$ John's, Newfoundland, Canada. The clearness index ranges from 0.20 to 0.30 . The solar insolation ranges from $1.28 \mathrm{~kW} / \mathrm{m}^{2} /$ day to $5.14 \mathrm{kWh} / \mathrm{m}^{2} /$ day, with a mean of $3.15 \mathrm{kWh} / \mathrm{m}^{2} /$ day.

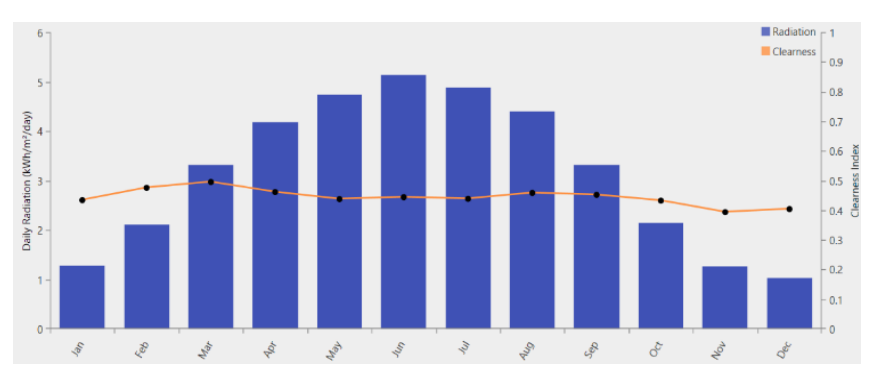

Fig. 1 Solar insolation and clearness index of selected site.

\section{B. Sites Power Requirement from BEopt}

BEopt software was used to estimate the annual power requirement for the chosen site. The house's power requirement amounts to around $21111 \mathrm{kWh}$ per year. This includes all the loads in the home, including heaters, boilers, lightning, ventilation, and other considerations such as plugin loads.

\section{Sites Load and Photovoltaic Panel Area Calculation}

The site's load requirement comes to $57.8 \mathrm{kWh} /$ day with peak of $11.90 \mathrm{~kW}$. Fig. 2 illustrates the daily load profile (hourly load data) from HOMER, the hourly energy demand is starting to raise around $6 \mathrm{AM}$ and drops by $9 \mathrm{PM}$ with an all-time high between 6 PM and 7PM. Fig. 3 illustrates the seasonal load profile (hourly load data) from HOMER, November to April months is having per hour energy demand compared to May to October months.
Submitted on June 12, 2021.

Published on July 03, 2021.

Raghul Suraj Sundararajan, Memorial University of Newfoundland, Canada. (e-mail: rssundararaj@mun.ca)
M. Tariq Iqbal, Memorial University of Newfoundland, Canada. (e-mail: tariq ${ }^{\circledR}$ mun.ca) 


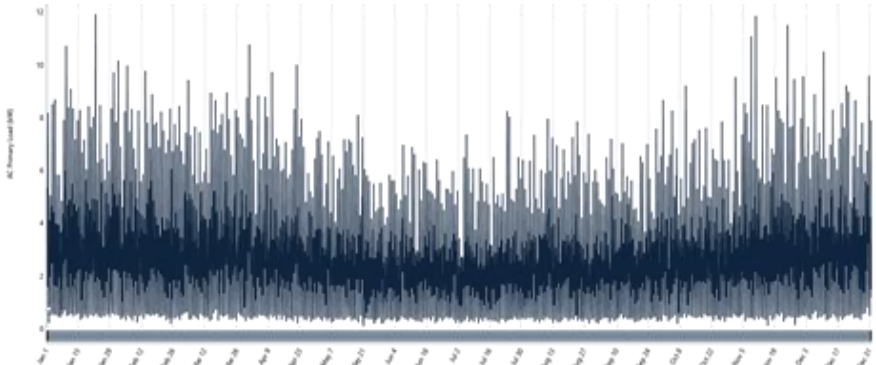

Fig. 2. Daily load chart (Hourly load data) from HOMER.

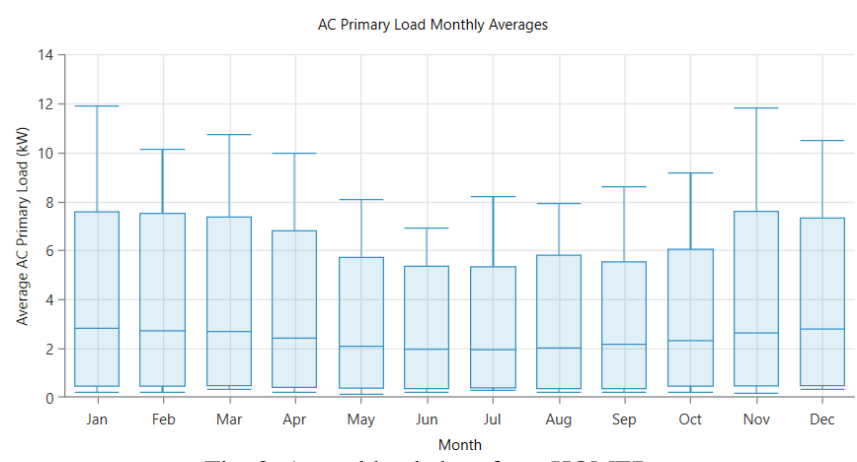

Fig. 3. Annual load chart from HOMER.

In St. John's, the average daily sunlight is 1633 hours for 272 days.

Output from BEopt $=21111 \mathrm{kWh} /$ year.

Per day $=57.8 \mathrm{kWh} /$ day.

Power output $=$ energy usage per day / number of full sun hours per day

$$
=12.930 \mathrm{~kW}
$$

For PV sizing considering derating factor as 0.8

= power output $/$ derating

$=16.1633 \mathrm{~kW}$.

PV size array $=$ Total calculated capacity of PV / $340 \mathrm{~W}$.

For calculated power output

$$
=38 \text { Modules. }
$$

For derating factor

$$
=48 \text { Modules. }
$$

\section{Area calculation}

Area of one Canadian solar CS6U $340 \mathrm{M}$ module is $1.88 \mathrm{~m}^{2}$.

For desired power output

$$
\begin{aligned}
& =38 \times 1.88 \\
& =71.44 \mathrm{~m}^{2} .
\end{aligned}
$$

For derating factor

$$
\begin{aligned}
& =48 \times 1.88 \\
& =90.24 \mathrm{~m}^{2} .
\end{aligned}
$$

Available area $=185.89 \mathrm{~m}^{2}$.

Bus voltage $=48 \mathrm{~V}$.

For desired power output, number of strings $=20$ Strings

Number of panels in each string $=2$.

Including derating factor the number of strings $=24$ Strings.

\section{SySTEM SIMULATION}

Hybrid Optimization of Multiple Energy Resources (HOMER) software was used for system sizing. Fig. 4 depicts a schematic of the proposed system. The PV panel used is a Canadian Solar CS6U- 340M, the battery is a Trojan SAGM 12105 , the inverter is a $20 \mathrm{~kW}, 10 \mathrm{~kW}$ genset which serves only as a backup and has no dynamic implications on the system, Nissan Leaf is added as deferrable load with $9.90 \mathrm{kWh} / \mathrm{d}$ with $6.60 \mathrm{~kW}$ peak and the home load profile is $57.80 \mathrm{kWh} / \mathrm{d}$ with a peak of $11.90 \mathrm{~kW}$.

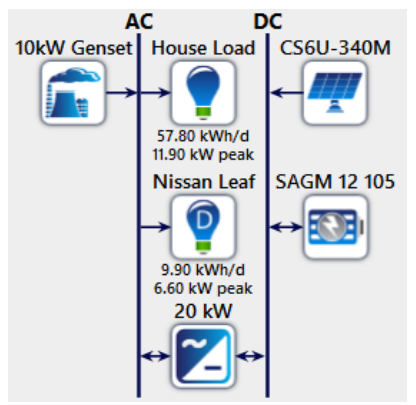

Fig. 4. Schematic of the proposed system in HOMER.

\section{A. Photovoltaic Panel}

The panel used in this design is the Canadian Solar CS6U $340 \mathrm{M}$, which has a $340 \mathrm{~W}$ output and a surface area of $1.8 \mathrm{~m}^{2}$.

\section{B. Battery}

Trojan SAGM 12105 battery was chosen for the application. The battery estimate is as follows, with three days of backup. As a result of the calculations, 360 batteries are required without backup. Since the design incorporated a $10 \mathrm{~kW}$ backup genset the number of batteries needed dropped to 80 numbers.

$$
\begin{aligned}
& \mathrm{Wh} / \text { day }=57804 \mathrm{Wh} / \text { day } \\
& 3 \text { days }=57804 \times 3=173413 \mathrm{Wh} \\
& 40 \% \mathrm{DOD}=173413 / 0.4=433532.5 \mathrm{Wh}
\end{aligned}
$$

Temp Cons $(>80 \mathrm{~F})=433532.5 \times 1=433532.5 \mathrm{Wh}$

Ah cap of Bt bank $=433532.5 / 48=9031.92 \mathrm{Ah}$

Number of Batteries $=(9031.92 / 100) 4=360$ Nos.

\section{Nissan Leaf - $40 \mathrm{~kW}$ variant}

This concept considers a Nissan Leaf with a 40-kW lithium-ion battery pack and a $6.6 \mathrm{~kW}$ onboard charger. Another advantage of the Nissan Leaf is that it has a built-in bidirectional converter for charging and discharging (reeling power to home). Nissan Leaf has two modes of operation: charging and discharging. When the Nissan Leaf is discharging or reeling out power. This is used when the PV panels and battery are unable to satisfy the energy demand of the home load [8], [9]. The following are presumed when the Nissan Leaf is in charging mode. The home loads are met, and the excess energy produced or stored is used to charge the electric vehicle [10]. Fig. 5 illustrates the Nissan Leaf $40 \mathrm{~kW}$ variant. 


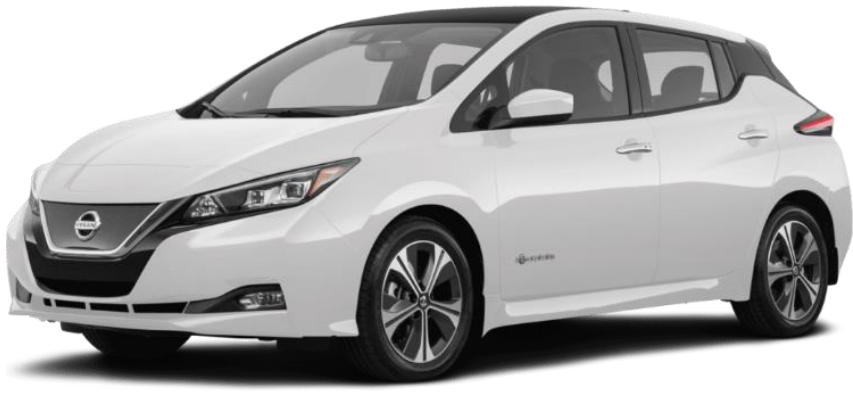

Fig. 5. Nissan Leaf 40kWh variant.

\section{Inverter}

Since the peak load is about $18.50 \mathrm{~kW}$, a $20 \mathrm{~kW}$ output power inverter is being considered for the design. The inverter in this case has two outputs: $120 \mathrm{~V}$ and $240 \mathrm{~V}$.

\section{SYSTEM DYNAMIC MODELLING}

Simulink was used to carryout simulation of the proposed architecture. It comprises of PV array, MPPT controller, inhouse battery, boost converters, inverter, level 1 charger, level 2 charger, Nissan Leaf battery. Fig. 6 illustrates the overall block diagram of the proposed system. The power produced by PV is used for charging the inhouse battery via a charger, inverter with two outputs $120 \mathrm{~V}$ and $240 \mathrm{~V}$ is implemented to convert the stored power in battery DC to AC to power the load. Furthermore, Nissan leaf charger with level 1 and level 2 charging feature [11] is implemented, a $10 \mathrm{~kW}$ genset is also incorporated which serves only as a backup and has no impact on dynamics of system and a converter is also implemented to stepdown $360 \mathrm{~V}$ to $48 \mathrm{~V}$, which is used for simultaneously charging the inhouse battery and powering the house loads [12], [13]. Fig. 7 illustrates the overview of simulated system. The system is simulated for charge and discharge of the inhouse battery, powering the loads using inhouse battery, dual output inverter that gives $120 \mathrm{~V}$ and $240 \mathrm{~V}$ as output, Nissan leaf charger with level 1 and level 2 charging, Discharge Nissan leaf to charge inhouse battery, discharge inhouse battery during night to charge Nissan leaf and dump load to drain excess power. The implemented system has automatic overrides for state of charge, namely $30 \%$ SOC charge ON (inhouse battery) and 40\% SOC charge ON (Nissan Leaf battery) for inhouse battery and Nissan Leaf, respectively as shown in Fig. 7. Fig. 7 illustrates the overview of the simulated system.

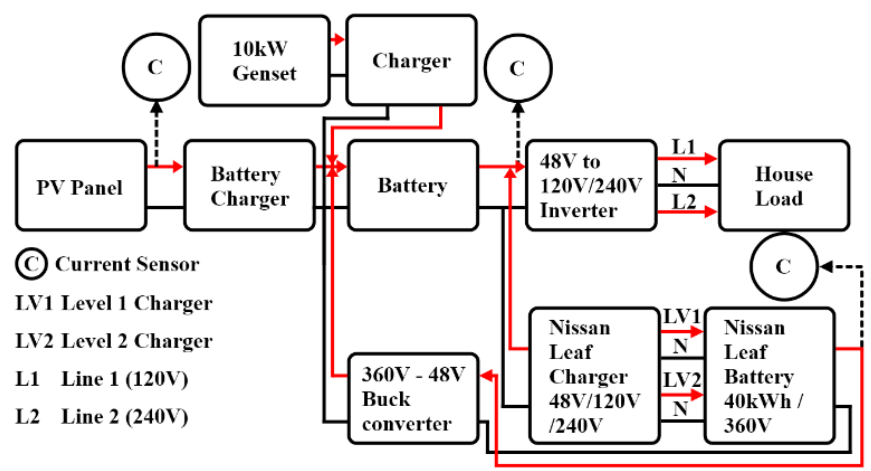

Fig. 6. Overall block diagram.

\section{A. MPPT Algorithm}

Maximum power point tracking (MPPT) is a concept that involves modifying PV impedance depending on varying irradiance to get the most power out of a PV panel. The Perturbation \& Observation $(\mathrm{P} \& \mathrm{O})$ algorithm is used by the MPPT controller in this simulation. The voltage is constantly perturbed in the $\mathrm{P} \& \mathrm{O}$ algorithm, and the inverter service cycle is modified depending on the performance observation. Even when there is a significant decrease or spike in irradiance, this algorithm is the best at tracking the maximum point. Fig. 8 illustrates the implemented MPPT algorithm $\mathrm{P} \& \mathrm{O}$ algorithm.

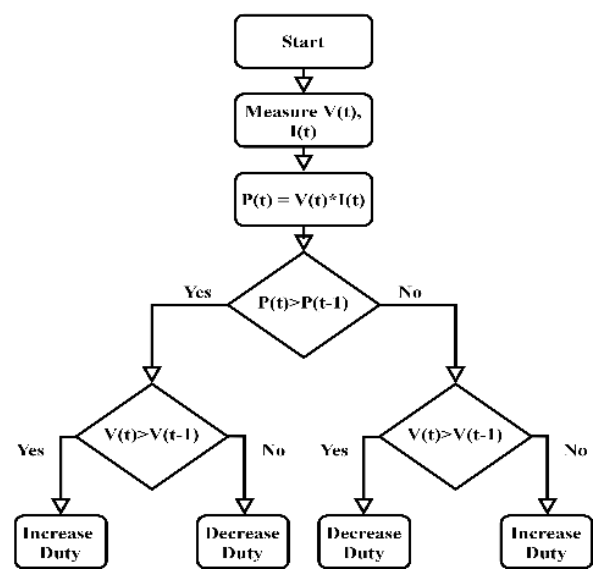

Fig. 8. Implemented MPPT Algorithm - P\&O Algorithm.

Furthermore, the simulation was carried out incorporating eight modes representing different modes [14] of operation.

\section{B. Mode 1-Inhouse Battery Charging Mode}

In this mode the output from PV is used for charging the inhouse battery and for powering the loads. In this case the loads energy demand is low. The excess energy is used for charging the battery. Fig. 9 illustrates switching control logic of the proposed system. From table 1, switches S1, S2, S3, S8, S9 turns ON and the switches S4, S5, S6, S7, S10, S11 remains OFF. Fig. 10 illustrates the charging design executed in MATLAB. From Fig. 10, the duty cycle from the MPPT block is fed into as the gate pulse for the MOSFET in the boost converter circuit. Fig. 11 and 12 illustrates the low load's current and voltage graph. The load has a voltage of $120 \mathrm{~V}$ and current of $12 \mathrm{~A}$.

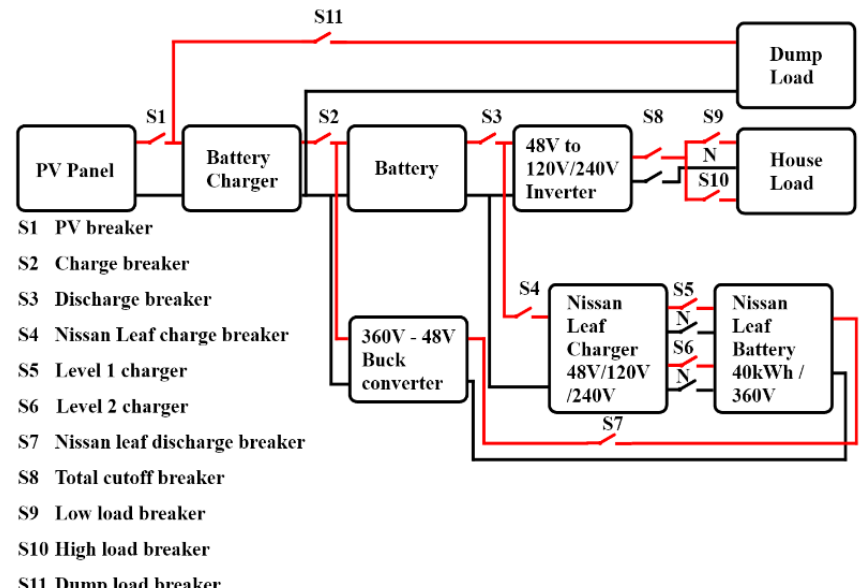

Fig. 9. Switching control logic of the system. 


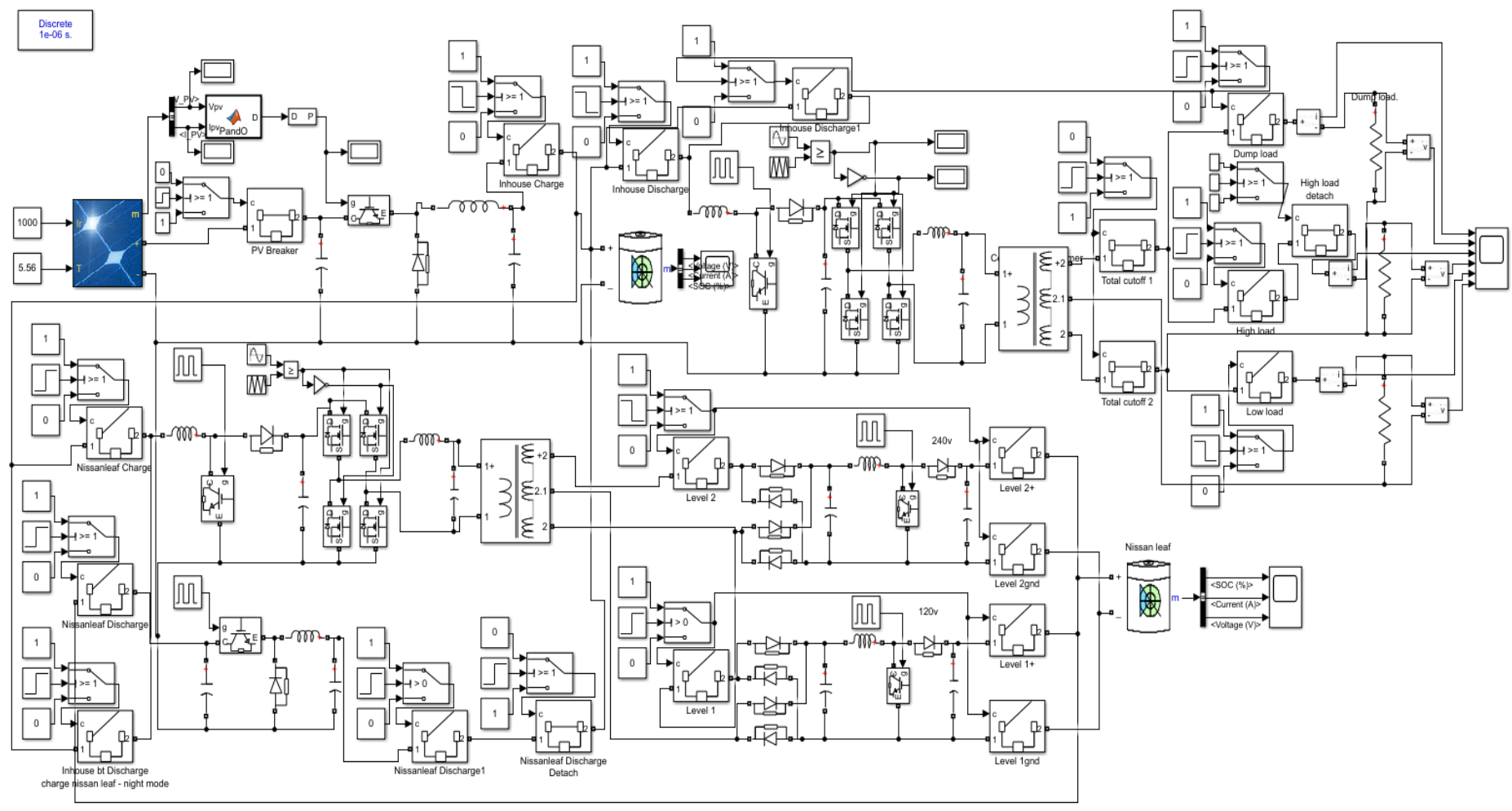

Fig. 7. Overview of simulated system.

TABLE I: CONTROL LOGIC OF THE PROPOSED SYSTEM

\begin{tabular}{|c|c|c|c|c|c|c|c|c|c|c|c|}
\hline Modes & S1 & $\mathrm{S} 2$ & $\mathrm{~S} 3$ & $\mathrm{~S} 4$ & S5 & S6 & S7 & S8 & S9 & S10 & S11 \\
\hline Mode 1 & $\mathrm{ON}$ & ON & ON & OFF & OFF & OFF & OFF & ON & $\mathrm{ON}$ & OFF & OFF \\
\hline Mode 2 & OFF & OFF & ON & OFF & OFF & OFF & OFF & $\mathrm{ON}$ & OFF & ON & OFF \\
\hline $\begin{array}{c}\text { Mode } 3 \\
\text { (Level 1) }\end{array}$ & ON & ON & ON & $\mathrm{ON}$ & $\mathrm{ON}$ & OFF & OFF & $\mathrm{ON}$ & $\mathrm{ON}$ & OFF & OFF \\
\hline $\begin{array}{c}\text { Mode } 3 \\
\text { (Level 2) }\end{array}$ & ON & ON & ON & $\mathrm{ON}$ & OFF & $\mathrm{ON}$ & OFF & ON & $\mathrm{ON}$ & OFF & OFF \\
\hline Mode 4 & OFF & OFF & OFF & OFF & OFF & OFF & $\mathrm{ON}$ & ON & OFF & $\mathrm{ON}$ & OFF \\
\hline Mode 5 & - & $\mathrm{ON}$ & $\mathrm{ON}$ & - & - & - & - & - & - & - & - \\
\hline Mode 6 & OFF & ON & OFF & OFF & OFF & OFF & OFF & OFF & - & - & OFF \\
\hline Mode 7 & ON & OFF & OFF & OFF & OFF & OFF & OFF & OFF & OFF & OFF & ON \\
\hline $\begin{array}{c}\text { Mode } 8 \\
\text { (Level 1) }\end{array}$ & OFF & OFF & ON & ON & ON & OFF & OFF & ON & ON & OFF & OFF \\
\hline $\begin{array}{c}\text { Mode } 8 \\
\text { (Level 2) }\end{array}$ & OFF & OFF & $\mathrm{ON}$ & $\mathrm{ON}$ & OFF & $\mathrm{ON}$ & OFF & ON & $\mathrm{ON}$ & OFF & OFF \\
\hline
\end{tabular}

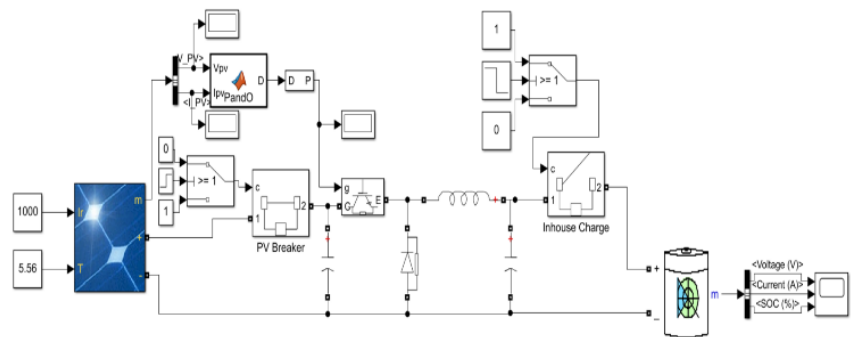

Fig. 10. Inhouse battery charging design in MATLAB.

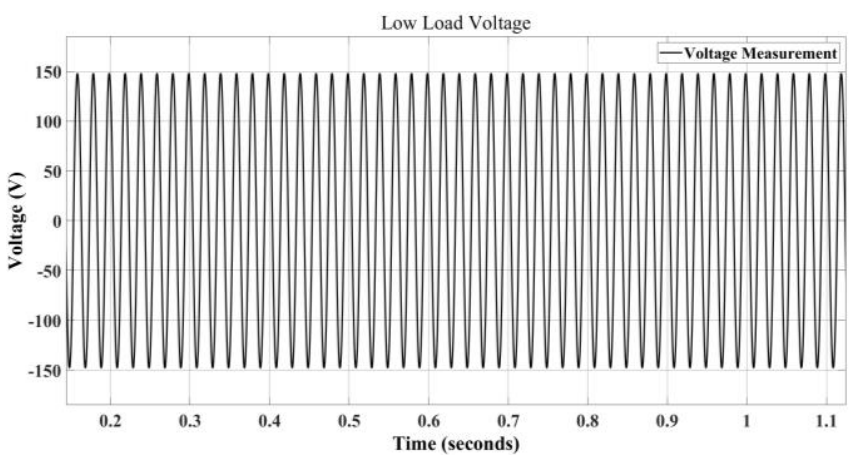

Fig. 11. Low load voltage graph.

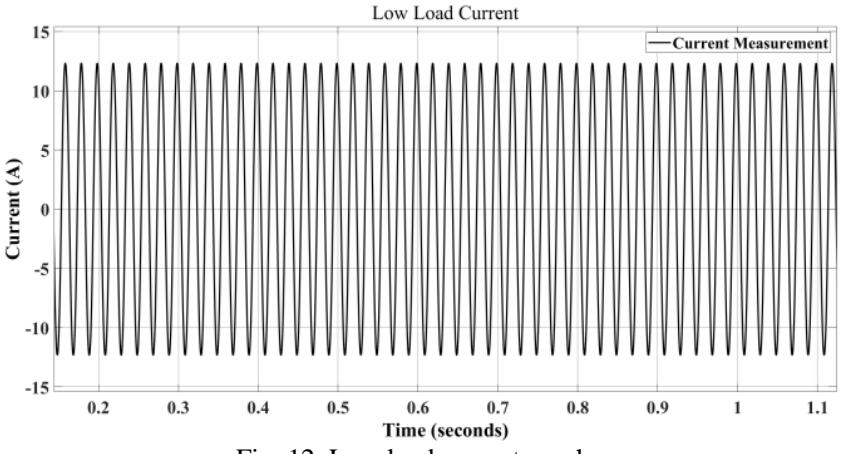

Fig. 12. Low load current graph.

\section{Mode 2-Inhouse Battery Discharge Mode}

In this mode the output from PV is low compared to the load's energy demand. In this case the inhouse battery is used to power the load. From Fig. 9 and Table I, in Mode 2 switches S3, S8, S10 turns ON and the remaining switches stays OFF. Fig. 13 illustrates the inhouse battery in discharge mode. Furthermore, a 2-output inverter is incorporated, that give $120 \mathrm{~V}$ and $240 \mathrm{~V}$ as output. Fig. 14 and 15 illustrate the 
high loads current and voltage graph. The load in this case has a voltage of $240 \mathrm{~V}$ and $27 \mathrm{~A}$.

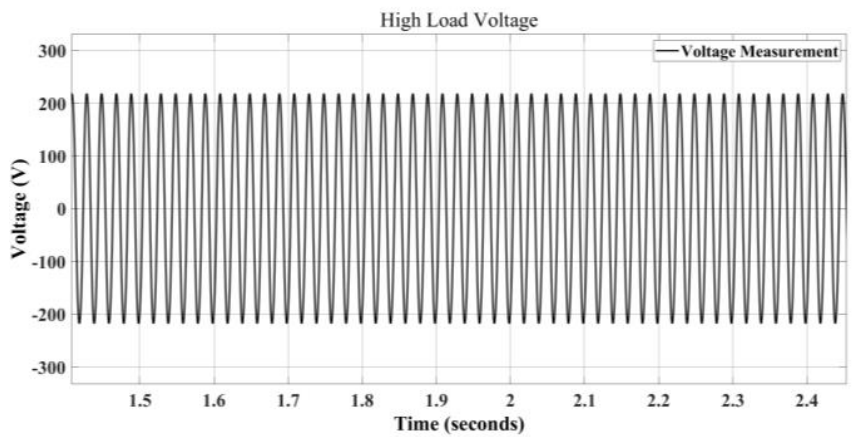

Fig. 14. High load voltage graph.

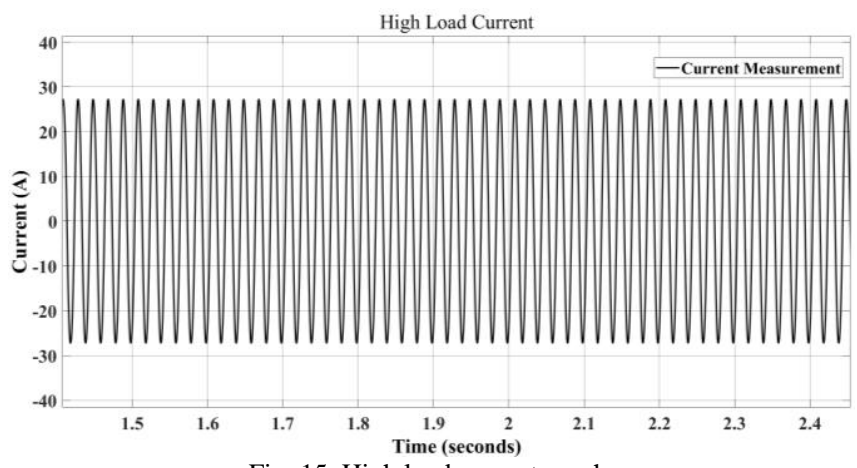

Fig. 15. High load current graph.

\section{A. Mode 3-Nissan Leaf Charge Mode}

In this mode output from PV is higher than the loads energy demand and the inhouse batteries SOC is greater than $60 \%$, the system will charge Nissan Leaf battery [14]. The implemented charger also comprises of level 1 (120V, $14 \mathrm{~A})$ and level $2(240 \mathrm{~V}, 20 \mathrm{~A})$ charging. Fig. 16 illustrates the Nissan leaf's charging mode. An inverter is incorporated to supply power for the level 1 and level 2 chargers. Furthermore, the chargers have incorporated boost converters to boost the voltage to $360 \mathrm{~V}$, charging voltage of Nissan Leaf battery. From Fig. 9 and Table I, in mode 3 at level 1 charging, switches S1, S2, S3, S4, S5, S8, S9 turns ON and switches S6, S7, S10, S11 remains OFF. In mode 3 level 2 charging, switches S1, S2, S3, S4, S6, S8, S9 turns ON and switches S5, S7, S10, S11 remains OFF. Fig. 17 and 18 illustrates the charging current graphs for level 1 and level 2 charging, respectively. The SOC of Nissan Leaf battery is illustrated in Fig. 19. The designed system has implemented both level 1 and level 2 charging, the output from level 2 charging can be seen between the time interval of 5 seconds to 10 seconds and the output from level 1 charging can be seen between the time interval of 10 seconds to 15 seconds [15], [16].

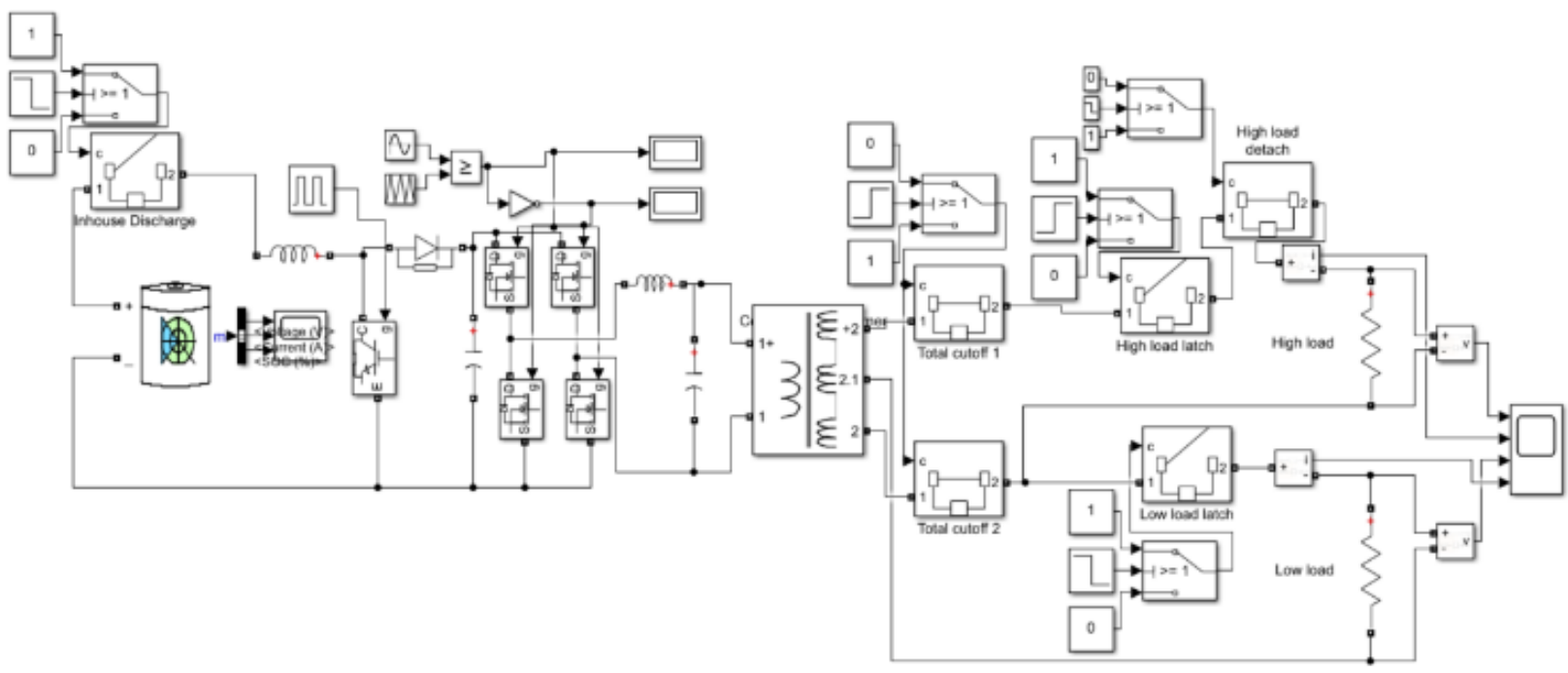

Fig. 13. Inhouse battery discharge design in MATLAB.

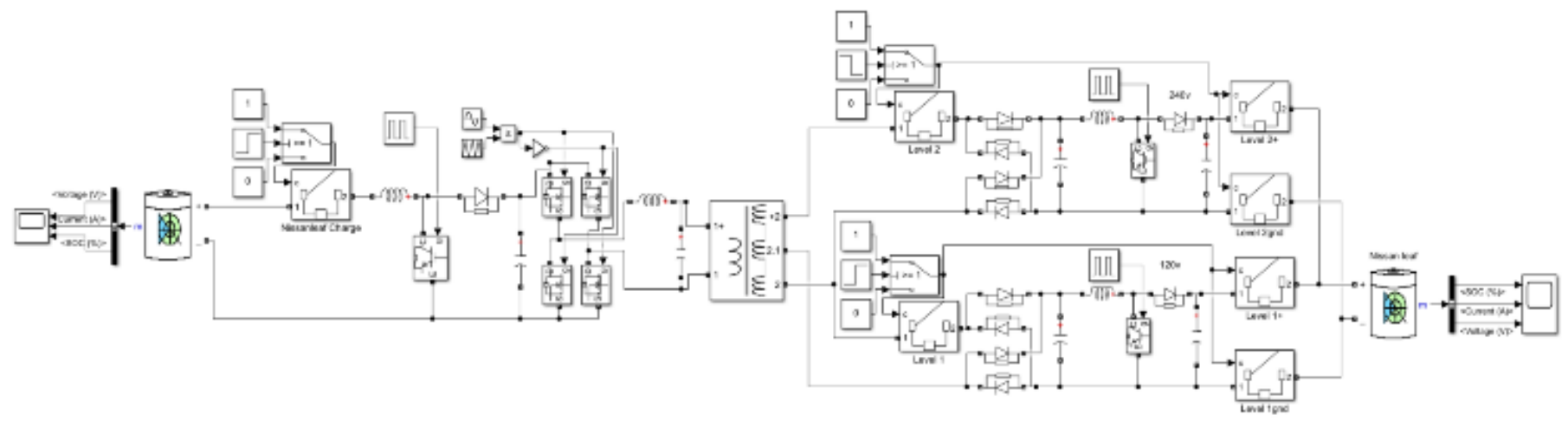

Fig. 16. Nissan Leaf's charging mode design in MATLAB. 


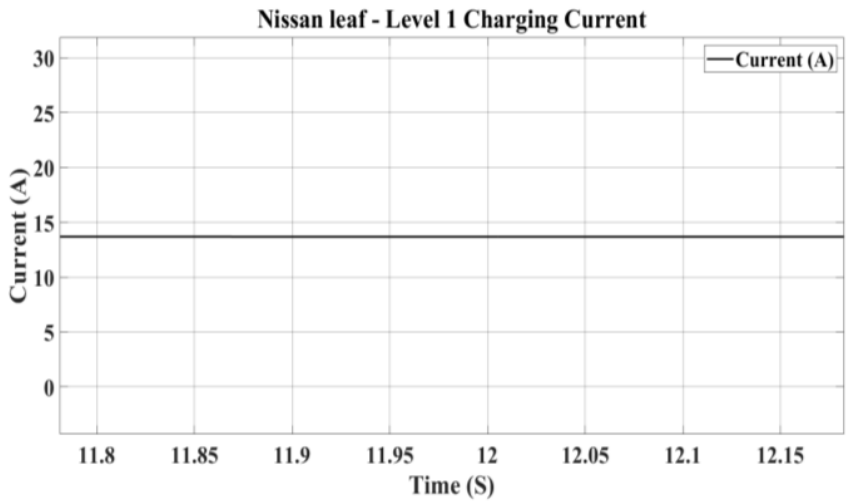

Fig. 17. Level 1 charging current graph.

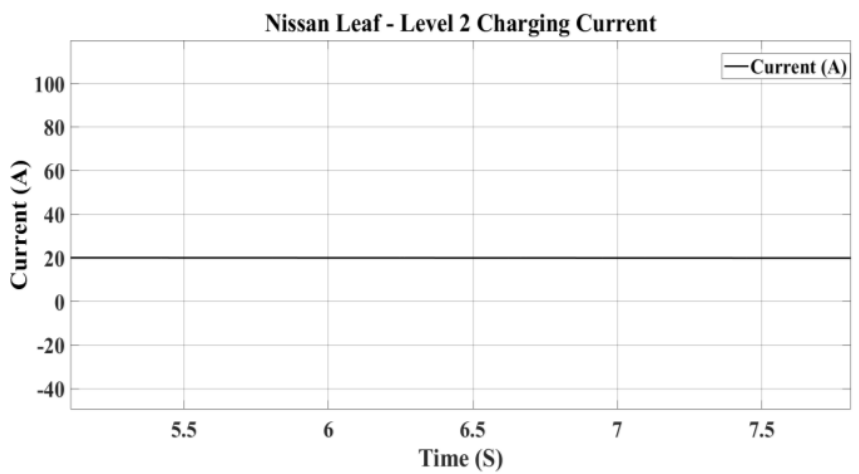

Fig. 18. Level 2 charging current graph.

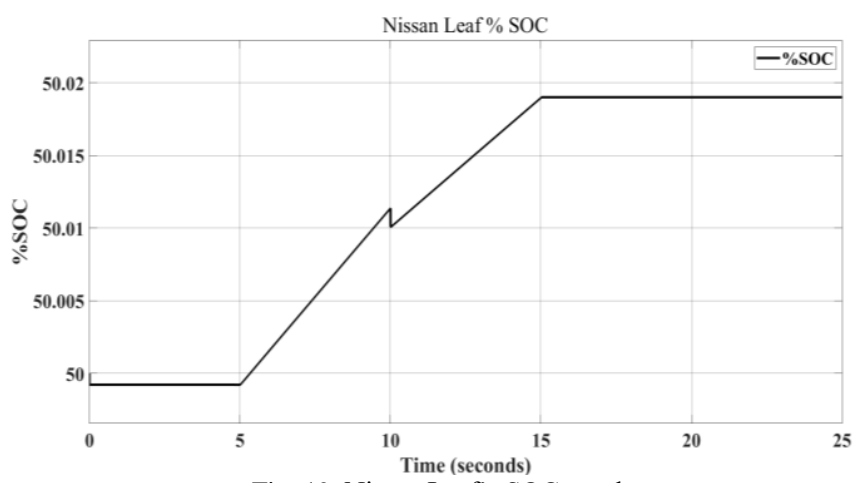

Fig. 19. Nissan Leaf’s SOC graph.

\section{B. Mode 4-Nissan Leaf Discharge Mode}

In this mode output from PV is less than the loads energy demand and the inhouse batterie SOC is less than $30 \%$, in this case Nissan Leaf is reels out the stored power to the house to meet the loads energy demand [17], [18]. From Fig. 9 and Table I, in mode 4 switches S7, S8, S10 are turned ON and remaining switches stay OFF. Fig. 20 illustrates the Nissan Leaf's discharge mode. A buck converter is incorporated to convert the high voltage $(360 \mathrm{~V})$ from the Nissan Leaf's battery to $48 \mathrm{~V}$ to charge the battery and power the load simultaneously [19], [20]. Fig. 21 illustrates the Nissan Leaf's SOC graph. From Fig. 21 the inhouse battery was on discharge cycle between the time intervals of 5 seconds to 15 seconds and then it has started to charge because of Nissan leaf's discharge mode execution.

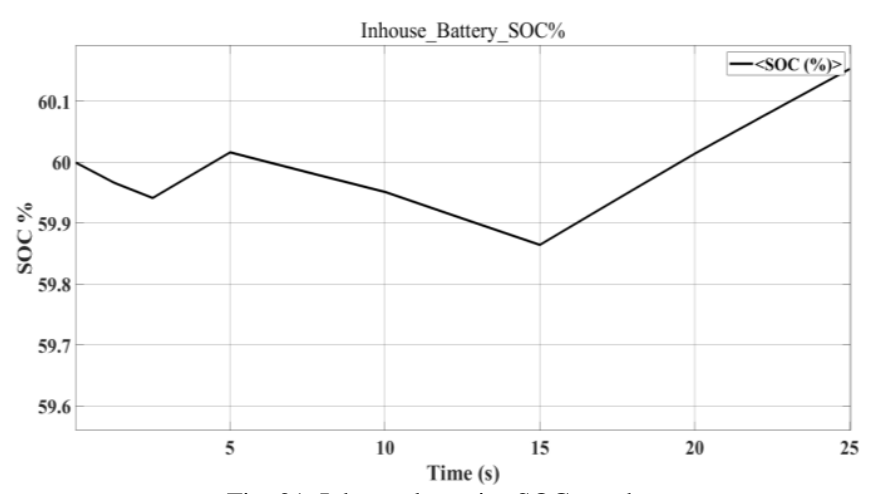

Fig. 21. Inhouse batteries SOC graph.

\section{Mode 5 - Inhouse Battery Protection Mode}

This mode is incorporated to help in saving the inhouse battery by monitoring the SOC of the battery. When inhouse batteries SOC falls to $30 \%$ SOC, the $30 \%$ SOC breaker goes $\mathrm{HIGH}$ and the $30 \%$ SOC charge on breaker goes HIGH to charge the battery. From Fig. 9 and Table I, switches S2, S3 turns $\mathrm{ON}$ and the remaining switches are OFF.

\section{Mode 6-System Isolation Mode}

In this mode output from PV is less than the loads energy demand, the inhouse batteries SOC is less than $30 \%$ and the Nissan leaf SOC is less than $40 \%$, [21] the total cutoff breaker is turned ON. This is executed to isolate the system from the Load so that the system does not fail. From Fig. 9 and Table I, in mode 6 switch S2 is turned ON to facilitate further charging of battery when PV starts producing power and switches S1, S3, S4, S5, S6, S7, S8, S9, S10, S11 remain OFF.

\section{E. Mode 7-Excess Power Handling Mode}

In this mode the power produced from PV is higher than the loads energy demand, the inhouse battery and Nissan Leaf's battery is charged, a dump load is implemented to dissipate the excess power. From Fig. 9 and Table I, in mode 7 switches $\mathrm{S} 1$ and $\mathrm{S} 11$ are turned $\mathrm{ON}$ and the switches S2, S3, S4, S5, S6, S7, S8, S9, S10 remains OFF.

\section{F. Mode 8-Nighttime Charging Mode}

In this mode is the power stored in the inhouse battery is used to charge Nissan leaf's battery at nighttime when the loads energy demand is considerably less and the inhouse batteries SOC is greater than 60\% [22]. From Fig. 9 and Table I, in Mode 8 level 1 charging, switches S3, S4, S5, S8, S9 is turned $\mathrm{ON}$ and the remaining switches $\mathrm{S} 1, \mathrm{~S} 2, \mathrm{~S} 6, \mathrm{~S} 7, \mathrm{~S} 10$, S11 stays OFF. Mode 8 level 2 charging mode, switches S3, S4, S6, S8, S9 are turned ON and the switches S1, S2, S5, S7, S10, S11 remains OFF. Fig. 22 illustrates the nighttime charging mode. From Fig. 22, the designed system has the option to choose between level 1 and level 2 charging even at nighttime charging mode. 


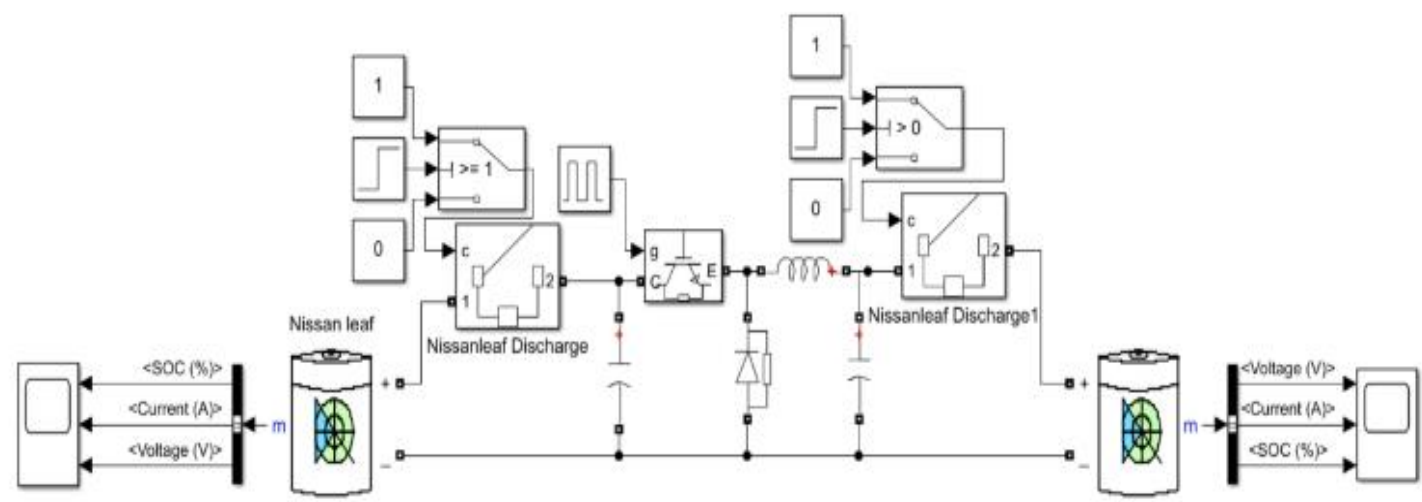

Fig. 20. Nissan Leaf's discharging mode design in MATLAB.

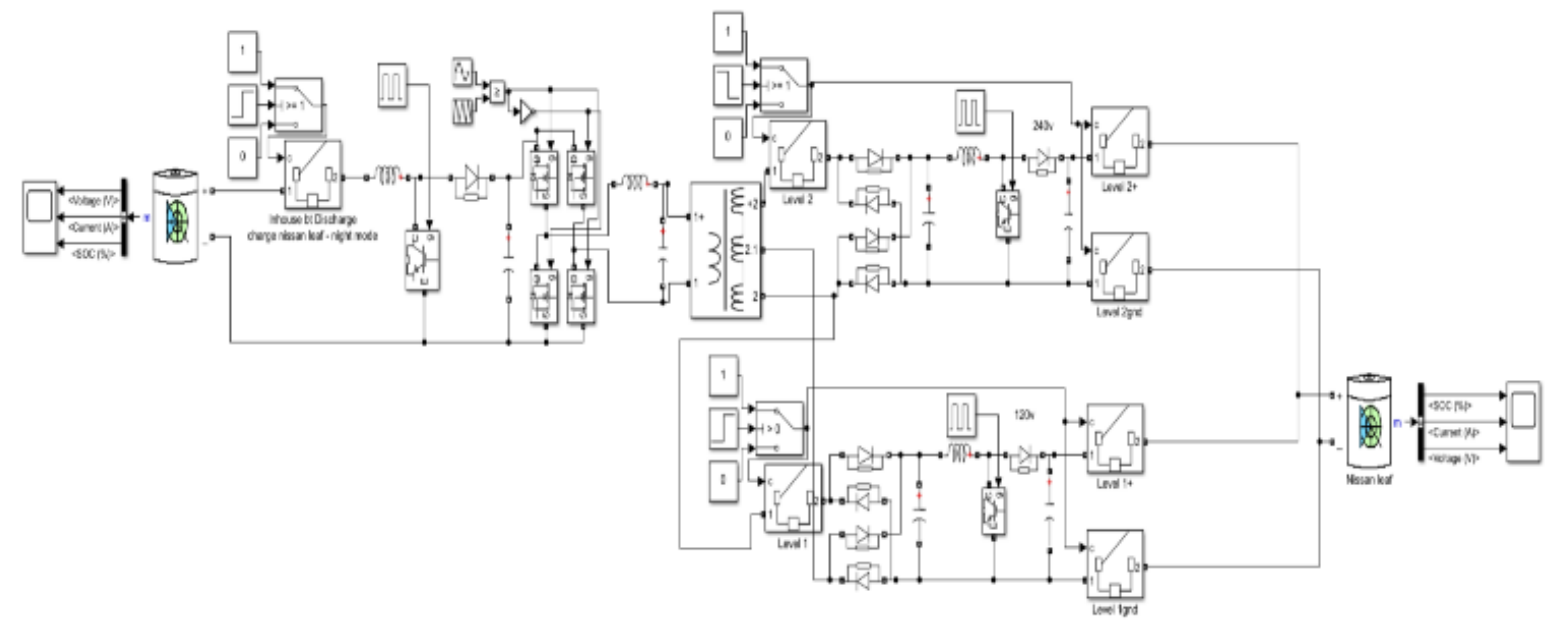

Fig. 22 Nighttime charging mode design in MATLAB.

\section{CONCLUSION}

Dynamic modelling of solar energy system with vehicle to home option for Newfoundland conditions was successfully designed and simulated. The solar insolation for Newfoundland from figure 1 is $3.15 \mathrm{kWh} / \mathrm{m}^{2} /$ day, PV panels considered are $340 \mathrm{~W}$ modules producing $16.3984 \mathrm{~kW}$ implemented in 24 strings with 2 panels in each string. A commercially available inverter of $20 \mathrm{~kW}$ capacity was incorporated with 80 Trojan SAGM 12105 batteries each of $12 \mathrm{~V}$ and 100 Ah along with a $10 \mathrm{~kW}$ backup genset, Nissan Leaf is implemented as deferrable load with $9.90 \mathrm{kWh} / \mathrm{d}$ with $6.60 \mathrm{~kW}$ peak. The implemented simulation consists of eight main operating modes i) Inhouse battery charging modepower produced by $\mathrm{PV}$ is used for charging the inhouse battery and for powering the loads simultaneously, ii) inhouse battery discharge mode - The stored power in the inhouse house battery is used to meet the loads energy demand, iii) Nissan Leaf charging mode - The loads energy demand is met and the inhouse battery is charged, the excess power is used for charging Nissan Leaf, iv) Nissan Leaf discharge mode- the loads energy demand is high and the output form PV and inhouse batteries SOC is low [23] Nissan Leaf reels out the stored energy to meet the loads energy demand [24], [25], v) inhouse battery protection mode - prevents the inhouse battery from going into degenerative discharge condition, vi) system isolation mode - to prevent the system from failing, vii) excess power handing mode - to handle the excess power produced, viii) nighttime charging mode - To charge Nissan Leaf to get it ready for next day's use. The implemented system has the scalability factor - can be extended to parking lots, multiple houses can be connected to form a microgrid and can power multiple houses or support the grid (V2G). Further this research would be directed towards V2X and V2G concept where vehicles would be used for sharing power to grid, scheduling loads, powering multiple houses, buildings or locality or an entire city and vehicle to vehicle energy transfers [26]-[30].

\section{ACKNOWLEDGMENT}

The authors would like to express their gratitude to LUX flavours PVT Ltd for funding the research.

\section{REFERENCES}

[1] S. Bracco, F. Delfino, G. Piazza, F. Foiadelli and M. Longo, "Nanogrids with Renewable Sources, Electrical Storage and Vehicleto-Home Systems in the Household Sector: Analysis for a SingleFamily Dwelling," 2019 IEEE Milan PowerTech, 2019, pp. 1-6, doi 10.1109/PTC.2019.8810757.

[2] L. Chandra and S. Chanana, "Energy Management of Smart Homes with Energy Storage, Rooftop PV and Electric Vehicle," 2018 IEEE International Students' Conference on Electrical, Electronics and Computer Science (SCEECS), 2018, pp. 1-6, doi: 10.1109/SCEECS.2018.8546857.

[3] F. Berthold, B. Blunier, D. Bouquain, S. Williamson and A. Miraoui, "PHEV control strategy including vehicle to home (V2H) and home to vehicle (H2V) functionalities," 2011 IEEE Vehicle Power and Propulsion Conference, 2011, pp. 1-6, doi: 10.1109/VPPC.2011.6043120.

[4] R. Hemmati, H. Mehrjerdi, N. A. Al-Emadi and E. Rakhshani, "Mutual Vehicle-to-Home and Vehicle-to-Grid Operation Considering SolarLoad Uncertainty," 2019 2nd International Conference on Smart Grid and Renewable Energy (SGRE), 2019, pp. 1-4, doi: 10.1109/SGRE46976.2019.9020685. 
[5] S. Rezaee, E. Farjah and B. Khorramdel, "Probabilistic Analysis of Plug-In Electric Vehicles Impact on Electrical Grid Through Homes and Parking Lots," in IEEE Transactions on Sustainable Energy, vol. 4, no. 4, pp. 1024-1033, Oct. 2013, doi: 10.1109/TSTE.2013.2264498.

[6] F. Berthold, A. Ravey, B. Blunier, D. Bouquain, S. Williamson and A. Miraoui, "Design and Development of a Smart Control Strategy for Plug-In Hybrid Vehicles Including Vehicle-to-Home Functionality," in IEEE Transactions on Transportation Electrification, vol. 1, no. 2, pp. 168-177, Aug. 2015, doi: 10.1109/TTE.2015.2426508.

[7] N. Z. Xu and C. Y. Chung, "Reliability Evaluation of Distribution Systems Including Vehicle-to-Home and Vehicle-to-Grid," in IEEE Transactions on Power Systems, vol. 31, no. 1, pp. 759-768, Jan. 2016, doi: 10.1109/TPWRS.2015.2396524.

[8] C. Liu, K. T. Chau, D. Wu and S. Gao, "Opportunities and Challenges of Vehicle-to-Home, Vehicle-to-Vehicle, and Vehicle-to-Grid Technologies," in Proceedings of the IEEE, vol. 101, no. 11, pp. 24092427, Nov. 2013, doi: 10.1109/JPROC.2013.2271951.

[9] H. Shin and R. Baldick, "Plug-In Electric Vehicle to Home (V2H) Operation Under a Grid Outage," in IEEE Transactions on Smart Grid, vol. 8, no. 4, pp. 2032-2041, July 2017, doi 10.1109/TSG.2016.2603502.

[10] N. Z. Xu, K. W. Chan, C. Y. Chung and M. Niu, "Enhancing Adequacy of Isolated Systems With Electric Vehicle-Based Emergency Strategy," in IEEE Transactions on Intelligent Transportation Systems, vol. 21, no. 8, pp. 3469-3475, Aug. 2020, doi: 10.1109/TITS.2019.2929767.

[11] Y. Wi, J. Lee and S. Joo, "Electric vehicle charging method for smart homes/buildings with a photovoltaic system," in IEEE Transactions on Consumer Electronics, vol. 59, no. 2, pp. 323-328, May 2013, doi: 10.1109/TCE.2013.6531113

[12] B. Kim, "Smart charging architecture for between a plug-in electrical vehicle (PEV) and a smart home," 2013 International Conference on Connected Vehicles and Expo (ICCVE), 2013, pp. 306-307, doi: 10.1109/ICCVE.2013.6799811.

[13] V. Monteiro, J. G. Pinto and J. L. Afonso, "Operation Modes for the Electric Vehicle in Smart Grids and Smart Homes: Present and Proposed Modes," in IEEE Transactions on Vehicular Technology, vol. 65, no. 3, pp. 1007-1020, March 2016, doi: 10.1109/TVT.2015.2481005.

[14] V. Monteiro, T. J. C. Sousa, C. Couto, J. S. Martins, A. A. N. Melendez and J. L. Afonso, "A Novel Multi-Objective Off-Board EV Charging Station for Smart Homes," IECON 2018 - 44th Annual Conference of the IEEE Industrial Electronics Society, 2018, pp. 1983-1988, doi: 10.1109/IECON.2018.8591325.

[15] X. Wu, X. Hu, X. Yin and S. J. Moura, "Stochastic Optimal Energy Management of Smart Home With PEV Energy Storage," in IEEE Transactions on Smart Grid, vol. 9, no. 3, pp. 2065-2075, May 2018, doi: 10.1109/TSG.2016.2606442.

[16] A. Ito, A. Kawashima, T. Suzuki, S. Inagaki, T. Yamaguchi and Z. Zhou, "Model Predictive Charging Control of In-Vehicle Batteries for Home Energy Management Based on Vehicle State Prediction," in IEEE Transactions on Control Systems Technology, vol. 26, no. 1, pp. 51-64, Jan. 2018, doi: 10.1109/TCST.2017.2664727.

[17] J. Gupta and B. Singh, "A Bidirectional Home Charging Solution for an Electric Vehicle," 2019 IEEE International Conference on Environment and Electrical Engineering and 2019 IEEE Industrial and Commercial Power Systems Europe (EEEIC / I\&CPS Europe), 2019 pp. 1-6, doi: 10.1109/EEEIC.2019.8783612.

[18] V. Monteiro, B. Exposto, J. C. Ferreira and J. L. Afonso, "Improved Vehicle-to-Home (iV2H) Operation Mode: Experimental Analysis of the Electric Vehicle as Off-Line UPS," in IEEE Transactions on Smart Grid, vol. 8, no. 6, pp. 2702-2711, Nov. 2017, doi: 10.1109/TSG.2016.2535337.

[19] D. P. Tuttle, R. L. Fares, R. Baldick and M. E. Webber, "Plug-In Vehicle to Home (V2H) duration and power output capability," 2013 IEEE Transportation Electrification Conference and Expo (ITEC), 2013, pp. 1-7, doi: 10.1109/ITEC.2013.6574527.

[20] Y. Wang, O. Sheikh, B. Hu, C. Chu and R. Gadh, "Integration of V2H/V2G hybrid system for demand response in distribution network," 2014 IEEE International Conference on Smart Grid Communications (SmartGridComm), 2014, pp. 812-817, doi: 10.1109/SmartGridComm.2014.7007748.

[21] C. Quinn, D. Zimmerle and T. H. Bradley, "An Evaluation of State-ofCharge Limitations and Actuation Signal Energy Content on Plug-in Hybrid Electric Vehicle, Vehicle-to-Grid Reliability, and Economics," in IEEE Transactions on Smart Grid, vol. 3, no. 1, pp. 483-491, March 2012, doi: 10.1109/TSG.2011.2168429.

[22] H. Turker, "Optimal Charging of Plug-in Electric Vehicle (PEV) in Residential Area," 2018 IEEE Transportation Electrification Conference and Expo (ITEC), 2018, pp. 243-247, doi: 10.1109/ITEC.2018.8450125
[23] L. S. de Souza Pelegrino, M. L. Heldwein and G. Waltrich, "Lowintrusion vehicle-to-home concept," 2016 International Conference on Electrical Systems for Aircraft, Railway, Ship Propulsion and Road Vehicles \& International Transportation Electrification Conference (ESARS-ITEC), 2016, pp. 1-6, doi: 10.1109/ESARS ITEC.2016.7841410

[24] M. S. Shemami, M. S. Alam and M. S. J. Asghar, "Load shedding mitigation through plug-in electric Vehicle-to-Home (V2H) system," 2017 IEEE Transportation Electrification Conference and Expo (ITEC), 2017, pp. 799-804, doi: 10.1109/ITEC.2017.7993371.

[25] M. S. Shemami, S. M. Amrr, M. S. Alam and M. S. Jamil Asghar, "Reliable and Economy Modes of Operation for Electric Vehicle-toHome (V2H) System," 2018 5th IEEE Uttar Pradesh Section International Conference on Electrical, Electronics and Computer Engineering (UPCON), 2018, pp. 1-6, doi 10.1109/UPCON.2018.8596932.

[26] D. T. Nguyen and L. B. Le, "Joint Optimization of Electric Vehicle and Home Energy Scheduling Considering User Comfort Preference," in IEEE Transactions on Smart Grid, vol. 5, no. 1, pp. 188-199, Jan. 2014 doi: 10.1109/TSG.2013.2274521

[27] F.Luo, G. Ranzi, W. Kong, Z.Y. Dong, F. Wang, "Coordinated residential energy resource scheduling with vehicle-to-home and high photovoltaic penetration" in 2018 IET Renewable Power Generation, vol. 12 , issue 6 .

[28] S. Pal and R. Kumar, "Electric Vehicle Scheduling Strategy in Residential Demand Response Programs with Neighbor Connection," in IEEE Transactions on Industrial Informatics, vol. 14, no. 3, pp. 980 988, March 2018, doi: 10.1109/TII.2017.2787121.

[29] D. Guo, P. Yi, C. Zhou and J. Wang, "Optimal electric vehicle scheduling in smart home with V2H/V2G regulation," 2015 IEEE Innovative Smart Grid Technologies - Asia (ISGT ASIA), 2015, pp. 1 6, doi: 10.1109/ISGT-Asia.2015.7387135.

[30] H. C. Güldorum, İ. Şengör and O. Erdinç, "Charging Management System for Electric Vehicles considering Vehicle-to-Vehicle (V2V) Concept," 2020 12th International Conference on Electrical and Electronics Engineering (ELECO), 2020, pp. 188-192, doi: 10.1109/ELECO51834.2020.00050. J. U. Duncombe, "Infrared navigation-Part I: An assessment of feasibility," IEEE Trans Electron Devices, vol. ED-11, pp. 34-39, Jan. 1959.

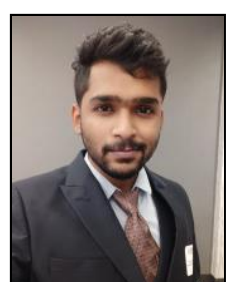

Raghul Suraj Sundararajan (member IEEE) was born on 27th September 1995 in Coimbatore, TamilNadu, India. Completed his B.Tech degree in mechatronics engineering from SRMIST, Chennai, TamilNadu, India by 2017.

He works as a TEACHING ASSISTANT and SYSTEM DESIGNER at Memorial University of Newfoundland, St. John's, Canada, and Dotndash respectively. Presently, he is a graduate student and doing a research based M.Eng in electrical engineering. He has published conference papers on "Design of an IoT interface for a solar energy system with vehicle to home option for Newfoundland conditions" in IEEE IEMCON 2020, Canada, "Design of solar parking lot for 20 electric vehicles in St. John's, NL" in IEEE NECEC 2020, Canada and "Dynamic simulation of an Isolated Solar Powered Charging Facility for 20 Electric Vehicles in St. John's, Newfoundland" in IEEE NECEC 2020, Canada. Currently, his research focuses on the "Design of Vehicle to Grid energy system for Newfoundland conditions".

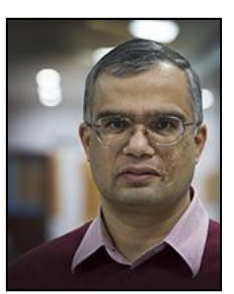

M. Tariq Iqbal received the B.Sc. (EE) degree from the University of Engineering and Technology, Lahore in 1986, the M.Sc. Nuclear Engineering degree from the Quaid-e-Azam University, Islamabad in 1988, and the Ph.D. degree in Electrical Engineering from the Imperial College London in 1994. Since 2001 he is working at the Faculty of Engineering and Applied Science, Memorial University of Newfoundland. Presently he is full Professor. His teaching activities cover a range electrical engineering topic, including renewable energy systems and power electronics. Currently, his research focuses on modeling and control of hybrid energy system. 